NASA Technical Memorandum 103736

\title{
A Reliability and Mass Perspective of SP-100 Stirling Cycle Lunar-Base Powerplant Designs
}

Harvey S. Bloomfield

Lewis Research Center Cleveland, Ohio

June 1991

\section{N/Sก}




\section{DISCLAIMER}

This report was prepared as an account of work sponsored by an agency of the United States Government. Neither the United States Government nor any agency Thereof, nor any of their employees, makes any warranty, express or implied, or assumes any legal liability or responsibility for the accuracy, completeness, or usefulness of any information, apparatus, product, or process disclosed, or represents that its use would not infringe privately owned rights. Reference herein to any specific commercial product, process, or service by trade name, trademark, manufacturer, or otherwise does not necessarily constitute or imply its endorsement, recommendation, or favoring by the United States Government or any agency thereof. The views and opinions of authors expressed herein do not necessarily state or reflect those of the United States Government or any agency thereof. 


\section{DISCLAIMER}

Portions of this document may be illegible in electronic image products. Images are produced from the best available original document. 


\title{
A RELIABILITY AND MASS PERSPECTIVE OF SP-100 STIRLING CYCLE
}

\section{LUNAR-BASE POWERPLANT DESIGNS}

\author{
Harvey s. Bloomfield \\ National Aeronautics and Space Administration \\ Lewis Research Center \\ Cleveland, Ohio 44135
}

\section{SUMMARY}

This report presents an approach to identifying high-reliability and lowmass space powerplant conceptual designs that are based on emerging or advanced technologies which have little or no reliability data base. The approach consists of estimating a range of expected unit reliabilities, or failure rates, for these emerging technology elements to determine the impact of varying the unit failure rates and of applying redundancy at various system levels on the overall reliability of powerplant designs. When combined with powerplant mass estimates, the resulting matrix can be used to characterize and select attractive powerplant design options as a function of the expected reliability of the emerging technologies.

The study applied this methodology to a lunar-base powerplant concept based on emerging SP-100 reactor heat source technology and stirling cycle power-generation technology. A range of reactor and power-generation unit reliability estimates was arbitrarily selected to allow for the uncertainty inherent in these emerging technologies, but only the boundaries of this range were used in the analysis. Reliability estimates of reactor and powergeneration subsystem units ranged from low, or pessimistic, values of 0.90 and 0.80 , respectively; to high, or optimistic, values of 0.98 and 0.95 .

A total of 80 lunar-base powerplant designs were investigated. These powerplants incorporated redundancy at two different levels, and each powerplant was required to produce at least $800 \mathrm{kWe}$ to meet an assumed mission success criterion. Design redundancy options at the highest system level included four different powerplant configurations:

(1) A nonredundant single system producing $800 \mathrm{kWe}$

(2) Two nonredundant 400-kwe systems operating in series to deliver $800 \mathrm{kWe}$

(3) Two fully redundant $800-k$ we systems operating in parallel

(4) Three partially redundant 400-kWe systems operating in a two-out-ofthree mode

At the lowest system level (the reactor and power-generation subsystem units), the powerplants had one of twenty different design redundancy options. Reactor subsystems were either single (nonredundant) or dual (fully redundant) parallel reactor units. Power-generation subsystems were composed of one to nine partially redundant $(k-o u t-o f-n)$ parallel power-generation units including up to two spare units.

As a result of this study some interesting perspectives on the characteristics and selection criteria of high-reliability and low-mass lunar-base powerplant design configurations have emerged. For example, as expected, the wide range of emerging-technology reliability estimates used had a significant 
effect on the selection of high-reliability and low-mass design configurations. Powerplant designs that provided high reliability with low mass when optimistic emerging technology reliability estimates were assumed were generally unacceptable when pessimistic reliability estimates were substituted. Therefore, to ensure acceptable powerplant reliability, one should select minimum mass configurations on the basis of pessimistic reliability estimates.

Another interesting result of the study was that for either low or high unit reliability estimates, the best combination of high powerplant reliability and low mass occurred when redundancy was applied at the lowest level of system hierarchy. Thus, the most attractive powerplant design concepts were nonredundant single-system powerplants with subsystem-unit redundancy options. Selection of the best redundancy option for the subsystem units, however, depended on the definition of an acceptable overall powerplant reliability criterion.

The issue of defining an acceptable overall powerplant reliability criterion was addressed, and the definition of this criterion significantly affected the selection of the best subsystem unit redundancy configuration. Since the calculated overall reliability of any powerplant configuration is highly dependent on the emerging technology reliability estimates, powerplant reliability is a relative value. Therefore, an acceptable reliability criterion must be defined on the basis of emerging technology reliability estimates. The reasonable choice appeared to be an acceptable reliability criterion that required the overall powerplant reliability to be equal to, or better than, any emerging technology subsystem unit reliability estimate. However, that selection required every acceptable powerplant configuration to have two fully redundant, parallel reactor units. Although dual reactors do not impose a significant mass penalty, they may require integration and operational considerations that were not fully explored in this study. Therefore, selecting an attractive powerplant design on the basis of an arbitrary reliability criterion may involve a tradeoff with design or operational complexity as well as with mass.

Additional perspectives into selecting the best redundancy options for the subsystem units were gained by analyzing the effect of varying the overall powerplant reliability criterion with estimates of emerging technology reliabilities. For example, with pessimistic emerging technology reliability estimates and a corresponding reliability criterion of approximately 0.90 or better, the lowest mass $800-k$ We powerplant configuration consisted of a single 800-kWe system composed of two fully redundant, parallel reactor units coupled to a total of six parallel, partially redundant 200-kWe power-generation subsystem units, of which two are spares. This configuration provided a powerplant reliability of 0.8921 at a mass of $26660 \mathrm{~kg}$. If higher overall powerplant reliabilities are desired, and additional mass is acceptable, fewer power-generation units are needed. For example, a decrease to five 267-kWe power-generation units, including two spares, provides a powerplant reliability of 0.9327 at a mass of $28320 \mathrm{~kg}$, and a further decrease to four 400-kWe power-generation units, including two spares, provides the highest singlesystem powerplant reliability of 0.9631 at a mass of $32340 \mathrm{~kg}$.

For optimistic emerging technology reliability estimates and a corresponding reliability criterion of 0.98 or better, the lowest mass powerplant, again, consisted of a single-system 800-kWe configuration. However, this 
configuration had two fully redundant reactor units coupled to nine 167-kWe power-generation units, including two spares. This configuration provided a powerplant reliability of 0.9898 at a mass of $25060 \mathrm{~kg}$. Decreasing the number of power-generation units again provides higher powerplant reliability at the expense of mass, up to a maximum of 0.9991 at a mass of $32340 \mathrm{~kg}$ for a four-unit power-generation subsystem, including two spares, with each unit rated at $400 \mathrm{kWe}$.

Reducing the acceptable reliability criterion to, say, the reliability of the lowest emerging technology subsystem unit allows single-unit reactor subsystems to be selected with a resultant powerplant mass decrease. For example, with pessimistic emerging-technology reliability estimates and a corresponding reliability criterion of approximately 0.80 or better, the lowest mass configuration was a single-system powerplant composed of only one reactor unit coupled to six parallel, partially redundant $200-k W e$ powergeneration subsystem units including two spares. This configuration provided a powerplant reliability of 0.8110 at a mass of $23360 \mathrm{~kg}$. If higher powerplant reliabilities are desired, a wide range of single unit reactor subsystem options are viable up to a reliability criterion of about 0.84 .

For optimistic emerging technology reliability estimates and a corresponding reliability criterion of 0.95 or better, the lowest mass conceptual design was a single-system powerplant composed of one reactor unit coupled to five 200-kWe partially redundant power-generation units with one spare. This configuration provided a powerplant reliability of 0.9578 at a mass of $21390 \mathrm{~kg}$. If higher powerplant reliabilities are desired, a wide range of single-unit reactor subsystem options are viable up to a reliability criterion of about 0.98 .

The perspectives developed in this study provided valuable insight into the considerations required to identify and characterize high-reliability and low-mass lunar-base powerplant designs. In general, this methodology can provide similar reliability perspectives for any space power mission designs based on emerging technologies with unknown reliabilities.

\section{INTRODUCTION}

As part of NASA's efforts to provide viable options for carrying out a focused program of human exploration of the solar system, its office of Exploration (now absorbed into the NASA Office of Aeronautics and Exploration Technology) desired to establish a knowledge-based understanding for a selection rationale. A series of illustrative cases and tradeoffs were studied to develop conceptual point designs and technical requirements and to understand the driving technology factors and operational considerations in choosing options. One pathway of human exploration was encompassed in a hypothetical lunar evolution case study. A permanent facility, with significant capabilities for operations, research, and self-support, would be established on the lunar surface. Then, lunar resources, including propellants, would be developed and exploited to reduce support requirements from Earth. Ultimately, these permanent facilities would be developed for expanded lunar operations and scientific activities to support expansion of the human presence into the solar system. 
In its role assigned by the NASA Office of Exploration as the special Assessment Agent for power and propulsion, the NASA Lewis Research Center developed a conceptual design to assess integration and operational issues for a proposed lunar-base powerplant that could provide about $800 \mathrm{kWe}$ (ref. 1). The powerplant concept was based on the SP-100 reactor heat source and stirling cycle dynamic power generation: emerging technologies that are currently being developed in government-sponsored programs and are projected for system technology validation by the late 1990's. The powerplant design has features that are highly compatible with a human-rated lunar base from the standpoints of nuclear safety and of potential for repair or replacement of nonnuclear subsystems.

From a reliability design configuration perspective, the reference powerplant consisted of a single power system composed of two serially connected subsystems: a reactor subsystem and a power-generation subsystem. The reactor subsystem consisted of a single (nonredundant) reactor unit, and the partially redundant power-generation subsystem contained eight parallel units, of which six were required to operate and two were spares (redundant). The reliability path diagram for this configuration (fig. 1) illustrates the nonredundant reactor subsystem and the partial (k-out-of $n$ ) redundancy employed in the power-generation subsystem.

In order to achieve mission success over an unspecified time period, the single reactor unit must be operating, and at least six out of eight powergeneration units must be operating concurrently. This design was selected to provide a reasonable combination of good reliability and low mass on the basis of previous analyses of reactor space power systems using dynamic power conversion subsystems (ref. 2). However, the configuration may not provide an acceptable overall powerplant reliability especially for potentially low, or pessimistic, estimates of reactor and power-generation subsystem unit reliabilities.

A key issue involved in assessing the reliability of this design - and, in general, for any power system using emerging technologies - is the estimation of unit reliabilities, or failure rates, for the emerging technologies. The lack of a substantial or relevant reliability data base for these technologies is a serious concern for powerplant designers attempting to meet a mission reliability requirement. A potential solution to this problem, however, is available at the early conceptual design stage. By selecting a range of anticipated reliabilities for the emerging technologies, the designer can, through the application of combinatorial reliability theory, predict the sensitivity of overall powerplant reliability to variation in powerplant design configuration. The results can then be used to select redundancy options to achieve high overall reliability.

This methodology yielded the following results for the reference lunarbase powerplant. For optimistic, upper-bound reliability estimates of 0.98 for the reactor unit and 0.95 for each power-generation unit, the resulting overall power system reliability was 0.9743 - about as high as the highest subsystem-unit reliability estimate. For pessimistic, lower-bound reactor and power-generation unit reliabilities of 0.90 and 0.80 , the resulting overall power system reliability was 0.7172 - significantly less than the highest subsystem-unit reliability estimate, and even lower than the lowest subsystemunit reliability estimate. This result clearly illustrates the deleterious 
effect of potentially low values of emerging-technology unit reliabilities on the overall reliability of the reference powerplant design.

Because of concern for overall powerplant reliability, especially for human-rated space missions, this study was undertaken to characterize powerplant configurations that could improve overall reliability, particularly for low estimates of emerging-technology reliability. The conflict between quality, as represented by reliability, and the outlay of resources, as represented by mass, is particularly prominent in space systems and has been the subject of numerous studies. This conflict cannot be circumvented, but it can be minimized through selective design. The mathematical techniques available to optimize redundancy and increase system reliability are well known. These techniques rely on varying disciplines ranging from reliability to optimization procedures. (For example, see ref. 3.) Since improvements in overall reliability through redundancy always come at the expense of additional mass, it is especially important to identify and characterize a wide variety of alternative low-mass powerplant configurations based on varying redundancy at different system hierarchy levels.

An important aspect of this study was the development of mass models incorporating all the design features of the original lunar-base powerplant concept. These models were used to estimate powerplant mass for all alternative powerplant conceptual designs considered, and the combined powerplant reliability and mass results defined a matrix from which attractive configuration options could be selected and evaluated. In addition, a simple reliability-improvement criterion was developed to focus on appropriate powerplant design selections at any level of desired powerplant reliability over the range of expected reactor and power-generation unit reliabilities. Thus, a method was formulated to select specific space power design configurations that provide high overall reliability in combination with low mass as a function of the unit reliabilities of the emerging technologies used.

\section{DESIGN RELIABILITY IMPROVEMENT}

The reliability of any system can generally be improved by using more reliable components and/or applying distributed redundancy at one or more levels of the system. For the conceptual designs under consideration, all subsystem units were assumed to have given, fixed levels of reliability. Distributed redundancy options were explored as the sole means to improve overall reliability. Redundancy can generally be categorized according to two criteria: the level(s) at which redundancy is applied, and the state of the redundant elements while the system is in operation. These criteria, and their application to alternative lunar-base design configurations, formed the basis for reliability improvement techniques evaluated in this study. In addition, all redundant elements were assumed to be independent, and their operation was described as either a "success" or a "failure" over a specified time interval.

The reference powerplant (ref. 1) design was analyzed to understand the reliability improvements that could be realized by applying redundancy at different levels of the system hierarchy. The reference powerplant had redundancy solely at the subsystem unit level, and then only partially (in the power-generation subsystem). Figure 2 depicts the reactor and powergeneration subsystem of the reference powerplant and shows the key components 
of each subsystem. For simplicity, only one of the eight identical powergeneration units is shown. The reference powerplant design configuration is described in detail next as a basis to characterize alternative design configurations.

The reference reactor subsystem consisted of (1) a single 2.5-MWt SP-100 reactor which included a fueled core, vessel structure, control rods and reflectors, instrumentation, controls, an instrument-rated conical radiation shadow shield, and a cylindrical neutron shield/bulkhead and (2) a primary heat-transport loop which included a pump, an accumulator, and inlet and outlet piping and manifolds. These components, with the exception of the manifolds, were located in a manmade surface excavation lined with the cylindrical bulkhead. The bulkhead was made of boron/aluminum which provided excavation support and shielding to limit soil activation and radiation from scattered thermal neutrons. The lunar soil beyond the bulkhead provided ample shielding protection for radiation-sensitive components and human activities on the adjacent lunar surface.

The power-generation subsystem was located entirely on the lunar surface and consisted of eight identical and independent units with two spares. Each unit was composed of

(1) A platform to support the manifold and engines

(2) A secondary heat-transport loop including a heat exchanger built into the stirling engine heater head, a pump, and an accumulator

(3) A 133-kWe-rated free-piston stirling cycle engine with a linear alternator

(4) A waste-heat transport loop including a heat exchanger built into the stirling engine's cold end, a pump, an accumulator, and a heatpipe radiator

(5) Power management and distribution components including an ac-to-dc convertor, a parasitic load resistor radiator, and an electrical transmission cable

As previously noted, this powerplant only provided a reliability of 0.7172 when low estimates of reactor and power-generation unit reliabilities of 0.9 and 0.8 , respectively, were assumed. Reliability was improved herein by applying a variety of redundancy options to the basic design concept. The following hierarchical definitions were used to clarify the redundancy options at various levels.

Powerplant The powerplant consisted of either one, two, or three power systems connected in either series or parallel to provide various forms of system level redundancy. A powerplant output power level of $800 \mathrm{kWe}$ indicated "successful" operation.

System Each power system was composed of two series-connected subsystems: a reactor subsystem and a power-generation subsystem. Power system output was fixed at either 400 or $800 \mathrm{kWe}$ to accommodate the various forms of system-level redundancy used to meet the $800-\mathrm{kWe}$ powerplant requirement.

Subsystem The reactor and power-generation subsystems were both composed of one or more units. All units within a given subsystem were identical and of equal reliability, and the reliability, or success probability, of any 
unit was assumed to be independent of both the number and the operational state of the other like units.

Reactor Subsystem The reactor subsystem was composed of either one or two parallel reactor units. Maximum unit output was limited to $2.5 \mathrm{MWt}$, and operation down to 25 percent partial-output was assumed to be acceptable.

Power-Generation Subsystem The power-generation subsystem consisted of multiple parallel units to provide various levels of $k$-out-of- $n$, or partial, redundancy. Each of the $n$ units was sized such that the required operating power level was achieved from $k$ units. Maximum unit power output was limited to $400 \mathrm{kWe}$ and no limit was set on minimum unit power output.

On the basis of these definitions, an option matrix of powerplant redundancy levels was established. The matrix contained 80 different design configurations that employed redundancy options at the system and subsystem unit level - 4 system-level options, 2 reactor subsystem options, and 10 powergeneration subsystem options.

The four 800-kWe powerplant system level configuration options were

(1) A single, nonredundant, 800-kWe power system operating at full power

(2) Two parallel, redundant, 800-kwe power systems, each assumed to be operating at half power

(3) Three 400-kwe power systems, each assumed to be operating at twothirds power in a partially redundant (two-out-of-three) mode

(4) Two nonredundant, 400-kWe, series-connected power systems

These system-level redundancy options are illustrated in figure 3 . Systemlevel redundancy options were not considered for power systems with smaller outputs because of the significant anticipated powerplant mass increases.

At the subsystem level, the two reactor subsystem options included a nonredundant, single 2.5-MWt unit operating at either full or 50-percent power, and two fully redundant 2.5-MWt units, each operating at either 50- or 25-percent power. Power-generation subsystem options were based on partialto-full redundancy $(k-o u t-o f-n)$ configurations and ranged from two-to-ten power-generation units including either zero, one, or two spare units. Total subsystem power output varied with specified system power level (i.e., 400 or $800 \mathrm{kWe}$ ), and unit power levels also depended on the number of operating and spare units used. For example, the smallest power-generation unit size of $58 \mathrm{kWe}$ was used in a 400-kWe subsystem (seven-out-of-eight) configuration. The largest power-generation unit size of $400 \mathrm{kWe}$ (based on current design limits for stirling engines) was used with either a 400-kWe subsystem (oneout-of-two) fully redundant configuration, or an 800-kWe subsystem (two-outof-three) configuration. Figure 4 shows a power-system-level reliability path diagram of a fully redundant two-unit reactor subsystem serially connected to a generic, k-out-of-n, partially redundant power-generation subsystem.

The second redundancy criterion to be defined is the operational state of the redundant elements while the powerplant is in operation. There are three possible operational redundancy states: active, standby, or combined active-standby. The active redundancy operational state was previously assumed for the reference powerplant design, and it is also assumed for all 
other designs considered in this study. In this state all redundant subsystem units are always "on" and operational at some fraction of rated capacity. Active redundancy is quite common in complex remote systems, such as space applications, where components are subjected to a hazardous environment. It eliminates the need for potentially unreliable decision, startup, and switching devices that would be required for parallel elements in a state of standby redundancy. It also eliminates the need for a controlled startup of a "cold" unit to full capacity in the event of a failure.

Active redundancy is also justified by the present design philosophy for most complex systems. Since redundancy is usually costly, many systems are designed, when possible, to begin a mission by using all available system capability. As failures occur, the performance of the system is degraded, but vital functions can still be performed. System "failure" occurs when the performance of the system falls below acceptable, or minimum, levels. This philosophy is particularly applicable to a human-rated application where active redundancy provides available system capability, and partial-power output from a degraded system can provide power for vital life-support functions.

For this study, however, a partial-power output requirement was not considered, and system "failure" was assumed to occur when powerplant power output fell below the rated capacity value of $800 \mathrm{kWe}$. In addition, there are some unaddressed operational questions associated with active redundancy that apply to partial-power operation. For example, in the purely active redundancy mode assumed in this study, all parallel units operating at partialpower are not only subject to the operational environment, they may also be operating far from their design points. Although it is generally expected that partial-power operation would lead to lower unit failure rates for the reactor, this may not be the case for power-generation units. Because of the limited knowledge base of the emerging technologies used in this study, these operational questions cannot be addressed until after further analytical and experimental evaluation.

It should also be noted that combined active-standby redundancy was not extensively evaluated herein. However, in certain situations this type of redundancy may increase overall reliability for systems and subsystems operating in k-out-of-n configurations. For example, reliability tradeoff studies based on varying the relationships between operating failure rate, standby failure rate, and the reliability of switching and startup can be more reliable for some combined active-standby configurations (ref. 4). However, these analyses require additional estimates of partial-power, standby, switching, and startup reliabilities for the various units. Given the extremely limited reliability data base associated with the emerging technologies considered for space nuclear power systems, evaluation of the combined active-standby redundancy mode was deemed to be beyond the scope of this study and was not pursued further. For the interested reader, the reliability characteristics and calculation techniques applicable to active-standby redundancy are discussed comprehensively in reference 4 .

\section{RELIABILITY ANALYSIS}

The objective of the reliability analysis was to determine the overall powerplant reliability of the various system and subsystem configurations investigated. Powerplant reliability was conservatively defined as the 
probability of providing a specified power output ( $800 \mathrm{kWe})$ for a fixed mission duration; no partial-power output states were specified.

The analysis dealt with active redundancy only, and it was assumed that the reliability of any active element was independent of the state of the other elements and that all elements within a given subsystem were identical. since the concern is with end-of-mission success, and it was presumed that a required mission time was specified (although not explicitly stated), the unit success probability could be treated as an assigned constant. That is, time dependency would likely play a part in the determination of a unit's success probability, but for this analysis the reliability of a given unit was just a specified constant.

Generalized equations for active and fully redundant parallel design configurations are well documented in standard reliability texts (e.g., ref. 5). However, the specific reliability summation expansion equations used for the partially redundant ( $k-o u t-o f-n)$ power-generation configurations investigated are not commonly documented and are included in appendix $A$ along with a complete tabulation of all powerplant, system, and subsystem reliability equations and analysis results.

The reliability analysis included twenty-six 400-kWe subsystem configurations and twenty-four 800-kWe subsystem configurations. These fifty configurations provided the reliability data base and system level building blocks for the four powerplant configuration options. In addition, a set of high and low estimates of subsystem unit reliabilities was analyzed for each subsystem configuration to evaluate overall powerplant reliability sensitivity to emerging technology reliability.

\section{MASS ANALYSIS}

Mass estimates were developed for the 50 subsystem design configurations. These estimates were based on a "from-the-ground-up" mass estimation for all components and are consistent with the mass estimates developed for the reference powerplant (ref. 1). A tabulation of subsystem mass values is included in appendix $A$ in conjunction with the reliability analysis results. Detailed mass breakdowns for reactor and power-generation subsystems and units are presented in appendix $B$. Reactor subsystem unit mass estimates were based on the use of a modified 2.5-MWt SP-100 reactor for both single- and dualreactor subsystem design options. A description of specific reactor unit modifications required for integration with stirling engines and operation in a lunar surface excavation is given in reference 1. Also, additional design modifications to specific reactor subsystem elements were made to reflect the mass savings due to partial-power operation. This was reflected in reduced masses for radiation shields, bulkhead/shields, heat-transport loops, and manifolds. Mass estimates for dual-reactor subsystem design concepts were based on individual excavations for each reactor subsystem and included 100-percent component redundancy (i.e., linear scaling of component mass) with the exception of the inlet and outlet manifolds. A larger shared inlet and outlet manifold was assumed for dual installations with a 33-percent mass increase above the single-reactor manifold estimate.

Power-generation subsystem mass estimates were based on linear scaling of component masses based on variations in number of units and electrical output 
per unit with the exception of the waste heat radiator and the power management and distribution elements, which were based on fixed specific mass values of $7.8 \mathrm{~kg} / \mathrm{m}^{2}$ and $2.1 \mathrm{~kg} / \mathrm{kWe}$, respectively. stirling engine/linear alternator unit mass estimates were taken from a recent scaling study (ref. 6) that provided engine/alternator specific mass as a function of electrical power. All single-cylinder stirling engine/alternator unit masses were conservatively based on a larger 113-percent rated power output engine to account for uncertainty, and actual engine operating power levels were conservatively assumed to be about 90 percent of the electrical output of the larger engine. For example, if four engines were required to supply $800 \mathrm{kWe}$, each engine must provide $200 \mathrm{kWe}$. However, the mass estimate for each engine was based on a 225-kWe engine operating at $200 \mathrm{kWe}$. In addition, a maximum rated output of $450 \mathrm{kWe}$ ( $400 \mathrm{kWe}$ actual) was assumed because of increased uncertainty in engine design at larger sizes.

\section{DISCUSSION OF RESULTS}

On the basis of analyses carried out in this study, specific conclusions were reached regarding selection of preferable powerplant, power system, and subsystem configurations of lunar surface powerplants required to meet an assigned 800-kWe electrical load at high reliability and low mass. The major conclusion derived from this effort was that a powerplant consisting of a single (nonredundant) power system composed of two reactor subsystem units and at least four power-generation subsystem units, including two spares, will provide low powerplant mass over a wide range of acceptable reliability criteria and subsystem unit reliability estimates.

of the four powerplant system design configurations investigated, the single 800-kWe system configuration was the most attractive from a reliability and mass perspective. This is clearly shown in figures 5 and 6 , which graphically display the study results in terms of reliability versus mass for all powerplant configurations. The four system configurations are denoted by different symbols, and the subsystem design configurations are defined by three numbers. The first number denotes the number of reactor units, the second denotes the total number of power-generation units, and the third number denotes the number of spare power-generation units. The connecting lines between the subsystem configuration design points are shown for clarity only; they indicate a design commonality of similar type redundancy for both reactor units and spare power-generation units. Actual connecting lines between similar configuration types are truly represented by horizontal lines of constant reliability. This type of graphic depiction will be shown in a discussion of mass-reliability envelopes.

Figure 5 displays results for estimated optimistic reactor and powergeneration unit reliability estimates of 0.98 and 0.95 , respectively, with a minimum acceptable powerplant reliability criterion cutoff value of 0.95 , equivalent to the lower power-generation unit reliability estimate. Figure 6 displays results for pessimistic unit reliability estimates of 0.90 and 0.80 with a minimum acceptable powerplant reliability criterion cutoff value of 0.80 , again, equivalent to the lower power-generation unit reliability estimate.

It is important to note that arbitrary selection of the lowest mass acceptable reliability system configuration at either one of the (high or low) 
subsystem reliability estimates will not guarantee minimum mass at an acceptable reliability for the other subsystem reliability estimate. For example, if an arbitrary acceptable overall powerplant reliability criterion is established as approximately equal to or greater than the highest subsystem unit reliability estimate, then the lowest mass powerplant configuration for the optimistic subsystem unit reliability estimates of 0.98 and 0.95 is a single nonredundant powerplant with either a (292) or a (241) subsystem configuration. As shown in figure 5 the (292) configuration has a total powerplant mass of $25060 \mathrm{~kg}$ and provides an overall reliability of 0.9898 , and the (241) configuration has powerplant mass and reliability values of $25260 \mathrm{~kg}$ and 0.9856 . However, when pessimistic reactor and power-generation unit reliability estimates of 0.90 and 0.80 are selected, the powerplant reliability drops to an unacceptable value of 0.7303 for the (292) configuration (not shown in fig. 6 because it is less than the overall reliability cutoff value) and 0.8110 for the $(241)$ configuration.

Therefore, minimum-mass powerplant configurations should be selected for pessimistic estimates of emerging technology unit reliability in order to ensure acceptable values of overall powerplant reliability. On this basis, the lowest mass powerplant that can provide an overall reliability of approximately 0.90 (equivalent to the highest unit reliability estimate) is a single system with a (262) configuration. This configuration provides a powerplant reliability of 0.8921 for pessimistic subsystem reliability estimates. If additional mass is acceptable and higher reliability is desired, the (252) subsystem configuration increases powerplant reliability to 0.9327 . This configuration exhibits a total mass of $28320 \mathrm{~kg}$, which is only 6 percent higher than the (262) configuration. If maximum powerplant reliability is desired and mass is not overly constrained, the (242) configuration provides significant reliability improvement to 0.9631 at a powerplant mass of $32340 \mathrm{~kg}$.

The study conclusions and results discussed to this point have been based on an acceptable powerplant reliability criterion keyed to the highest subsystem unit reliability estimate - either 0.98 or 0.90 . It is of interest, however, to illustrate the effect of varying the acceptable reliability criterion on the selection of minimum mass configurations for powerplant configurations based on single $800-k$ We power systems. This is qualitatively illustrated in table $I$, which ranks the system configurations according to mass as a function of acceptable system reliability criterion for the high and low subsystem reliability estimates. These results illustrate the wide variation in minimum mass system design configurations that occur for different assumptions of acceptable reliability criteria. In general, as the acceptable reliability criterion is relaxed, the number of acceptable system configurations increases and the mass ranking changes. When the acceptable reliability criterion drops below the lowest unit reliability estimates, single-reactorunit configurations emerge as acceptable single-system powerplants. For example, for optimistic unit reliability estimates, the (151) configuration with an overall powerplant reliability of 0.9578 yields the lowest mass for a 0.95 reliability criterion. For pessimistic unit reliability estimates, the (162) configuration with an overall powerplant reliability of 0.8110 yields the lowest mass for a 0.80 reliability criterion.

To facilitate the process of defining a reasonable compromise of mass and reliability, English developed an approach based on the delineation of a reliability versus minimum mass envelope (R.E. English, 1990, NASA Lewis Research Center, Cleveland, $\mathrm{OH}$, personal communication). This graphical 
technique is illustrated in figure 7 , which depicts the minimum mass powerplant configurations as a function of desired overall powerplant reliability for both pessimistic and optimistic subsystem unit reliabilities. The figure displays the actual reliability step function change associated with each powerplant configuration and provides a more realistic description of the results for use as a design tool.

\section{CONCLUDING REMARKS}

As a result of this study some interesting perspectives on the characteristics and selection criteria of high-reliability and low-mass lunar-base powerplant design configurations have emerged. For example, as expected, the wide range of emerging-technology reliability estimates used had a significant effect on the selection of high-reliability and low-mass design configurations. Powerplant designs that provided high reliability with low mass when optimistic emerging technology reliability estimates were assumed were generally unacceptable when pessimistic reliability estimates were substituted. Therefore, to ensure acceptable values of reliability, one should select minimum mass configurations on the basis of pessimistic reliability estimates.

Another interesting result of the study was that for either low or high reliability estimates, the best combination of high powerplant reliability and low mass occurred when redundancy was applied at the lowest level of system hierarchy. Thus, the most attractive powerplant design concepts were nonredundant, single-system powerplants with subsystem-unit redundancy options. Selection of the best redundancy option for the subsystems, however, depended on the definition of an acceptable overall powerplant reliability criterion.

The issue of defining an acceptable overall powerplant reliability criterion was addressed, and the definition of this criterion significantly affected the selection of the best redundancy configuration for the subsystem units. Since the calculated overall reliability of any powerplant configuration is highly dependent on the emerging technology reliability estimates, powerplant reliability is a relative value. Therefore, an acceptable reliability criterion must be defined on the basis of emerging technology reliability estimates. The reasonable choice appeared to be an acceptable reliability criterion that required the overall powerplant reliability to be equal to, or better than, any emerging technology subsystem unit reliability estimate. However, that selection required every acceptable powerplant configuration to have two fully redundant, parallel reactor units. Although dual-unit reactors do not impose a significant mass penalty, they may have integration and operational problems that were not fully explored in this study. Therefore, selecting an attractive powerplant design on the basis of an arbitrary reliability criterion may involve tradeoffs with design or operational complexity as well as with mass.

Additional perspectives into selecting the best redundancy options for the subsystem units were gained by analyzing the effect of varying the overall powerplant reliability criterion with estimates of emerging technology reliabilities. For example, with pessimistic emerging technology reliability estimates and a corresponding reliability criterion of approximately 0.90 or better, the lowest mass powerplant configuration consisted of a single system composed of two fully redundant, parallel reactor units coupled to six parallel, partially redundant power-generation subsystem units including two 
spares. This configuration provided a powerplant reliability of 0.8921 at a mass of $26660 \mathrm{~kg}$. If higher overall powerplant reliabilities are desired, and additional mass is acceptable, fewer power-generation units are needed. For example, a decrease to five power-generation units, including two spares, provides a powerplant reliability of 0.9327 at a mass of $28320 \mathrm{~kg}$, and a further decrease to four power-generation units, including two spares, provides the highest single-system powerplant reliability of 0.9631 at a mass of $32340 \mathrm{~kg}$.

For optimistic emerging technology reliability estimates and a corresponding reliability criterion of 0.98 or better, the lowest mass powerplant, again, consisted of a single-system configuration. However, this configuration was composed of two fully redundant reactor units coupled to nine partially redundant power-generation units with two spares. This configuration provided a powerplant reliability of 0.9898 at a mass of $25060 \mathrm{~kg}$. Decreasing the number of power-generation units, again, provides higher powerplant reliability at the expense of mass, up to a maximum of 0.9991 at a mass of $32340 \mathrm{~kg}$ for a four-unit power-generation subsystem with two spares.

Reducing the acceptable reliability criterion to, say, the reliability of the lowest emerging technology subsystem unit allows single-unit reactor subsystem configurations to be selected, with a resultant powerplant mass decrease. For example, with pessimistic emerging-technology reliability estimates and a corresponding reliability criterion of approximately 0.80 or better, the lowest mass configuration was a single-system powerplant composed of only one reactor unit coupled to six parallel, partially-redundant powergeneration subsystem units including two spares. This configuration provided a powerplant reliability of 0.8110 at a mass of $23360 \mathrm{~kg}$. If higher powerplant reliabilities are desired, a wide range of single-unit reactor subsystem options are viable up to a reliability criterion of about 0.84 .

For optimistic emerging technology reliability estimates and a corresponding reliability criterion of 0.95 or better, the lowest mass conceptual design was a single-system powerplant composed of one reactor unit coupled to five partially redundant power-generation units, including one spare. This configuration provided a powerplant reliability of 0.9578 at a mass of $21390 \mathrm{~kg}$. If higher powerplant reliabilities are desired, a wide range of single-unit reactor subsystem options are viable up to a reliability criterion of about 0.98 .

Another useful product of this study was the delineation of the minimum mass envelope in a plot of reliability versus powerplant mass. This approach provides easy visualization of the best mass and reliability designs and should be useful for future powerplant design studies.

Partial-power powerplant operation is an important area of consideration that has only been lightly touched on in this study. A mission-planning strategy that requires highly reliable "survival" level power will be essential for any manned planet-surface expedition. Any of the powerplant configurations studied herein for an 800-kWe mission success power level will provide significantly higher reliabilities at a lower survival power level. For example, using pessimistic reactor and power-generation unit reliability estimates, a single-system (162) configuration which provides an overall powerplant reliability of 0.8110 at a mass of $23360 \mathrm{~kg}$ for $800 \mathrm{kWe,} \mathrm{will}$ provide a reliability of 0.8999 at an assumed survival partial-power level of 
$400 \mathrm{kWe}$. The use of dual-reactor configurations can provide even more dramatic increases in survival power reliability. A single-system (262) configuration at $26660 \mathrm{~kg}$, which provided an overall powerplant reliability of 0.8921 at $800 \mathrm{kWe}$, will achieve a reliability of 0.9899 at $400 \mathrm{kWe}$. These results illustrate that reducing survival power level increases reliability in a very comforting way; an important factor for manned missions in a hostile environment. However, optimal powerplant configuration selection may change if mission "success" is redefined to emphasize a "survival" power level.

The methodology developed in this study provided valuable insight into the considerations required to identify and characterize high-reliability and low-mass lunar-base powerplant designs. In general, this methodology can provide similar reliability perspectives for any space power conceptual designs based on emerging technologies with unknown reliabilities.

\section{DISCLAIMER}

This report was prepared as an account of work sponsored by an agency of the United States Tever the United States Government nor any agency thereof, nor any of their Government. Neither the Unity, express or implied, or assumes any legal liability or responsibility for the accuracy, completeness, or usefulness of any information, apparatus, product, or bility for the accuracy, completeness, or use would not infringe privately owned rights. Referprocess disclosed, herein to any specific commercial product, process, or service by trade name, trademark, manufacturer, or otherwise does not necessarily constitute or imply its endorsement, recommendation, or favoring by the United States Government or any agency thereof. The views and opinions of authors expressed herein do not necessarily state or reflect those of the United States Government or any agency thereof. 
This appendix defines the symbols and provides the equations used in the reliability analysis.

Symbols

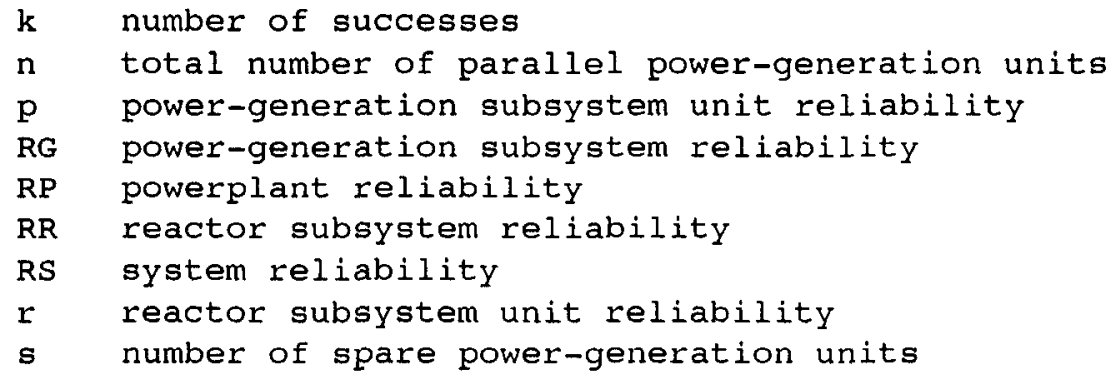

Powerplant Reliability Equations

The following equations were used to calculate overall powerplant reliability for the various levels of redundancy represented by the four powerplant types:

\begin{tabular}{|l|l|}
\hline \multicolumn{1}{|c|}{ Powerplant type } & \multicolumn{1}{|c|}{$\begin{array}{c}\text { Powerplant } \\
\text { reliability }\end{array}$} \\
\hline Single system (nonredundant) & RP $=\mathrm{RS}$ \\
Two parallel fully redundant systems & $\mathrm{RP}=\mathrm{RS}(2-\mathrm{RS})$ \\
Two series systems (nonredundant) & $\mathrm{RP}=\mathrm{RS}^{2}$ \\
Three partially redundant (two-out-of-three) systems & $\mathrm{RP}=3 \mathrm{RS}^{2}-2 \mathrm{RS}^{3}$ \\
\hline
\end{tabular}

System Reliability Equations

The following equations were used to calculate system reliability RS for the various levels of redundancy employed in the subsystem configurations:

$$
R S=(R R)(R G)
$$

where $R R=r$, for a single-reactor subsystem unit, or $R R=r(2-r)$, for two parallel, fully redundant reactor subsystem units, and

$$
R G=\sum_{k=(n-s)}^{n} \frac{n !}{(n-k) ! k !} p^{k}(1-p)^{n-k}
$$

for $n$ partially redundant, parallel power-generation subsystem units including $s$ spare units. 
The general summation expansion for RG reduces to simplified polynomials for the two-spares $(s=2)$ case.

The following table presents the polynomial expressions derived from the summation expansion for RG for power-generation subsystems employing from three-to-nine units $(3<n<9)$ with two spares $(s=2)$ :

\begin{tabular}{|c|c|}
$\begin{array}{c}\text { Total number of } \\
\text { parallel power- } \\
\text { generation units, } \\
n\end{array}$ & $\begin{array}{c}\text { Power-generation } \\
\text { subsystem } \\
\text { reliability, } \\
\text { RG }\end{array}$ \\
\hline 3 & $3 p-3 p^{2}+p^{3}$ \\
4 & $6 p^{2}-8 p^{3}+3 p^{4}$ \\
5 & $10 p^{3}-15 p^{4}+6 p^{5}$ \\
6 & $15 p^{4}-24 p^{5}+10 p^{6}$ \\
7 & $21 p^{5}-35 p^{6}+15 p^{7}$ \\
8 & $28 p^{6}-48 p^{7}+21 p^{8}$ \\
9 & $36 p^{7}-63 p^{8}+28 p^{9}$ \\
\hline
\end{tabular}

For $n$ partially-redundant power-generation subsystems using only one spare unit ( $s=1$ ), the summation expansion reduces to

$$
R G=n p^{n-1}-(n-1) p^{n}
$$

System Reliability and Mass Tabulation

Table II presents the matrix of reliability and mass results for single, nonredundant system configurations at two power levels, 400 and 800 kWe, and two levels of subsystem unit reliability. 
This appendix provides the detailed mass breakdown data used to generate total powerplant mass for 400- and 800-kwe system power outputs. It includes separate tabulations of reactor subsystem mass, power-generation subsystem mass, and total system mass.

\section{Reactor Subsystem Mass}

Table III presents the component breakdown of reactor subsystem mass elements for 400- and 800-kWe systems using one or two reactor subsystem units. Reactor mass values were conservatively based on a fixed thermal output of 2.5 MWt for all cases. Dual-reactor configurations are assumed to operate in parallel at 50 percent of required power and to share a single set of inlet and outlet manifolds with a 33-percent manifold mass penalty for additional primary-loop piping connections.

\section{Power-Generation Subsystem Mass}

For the power-generation subsystem mass, separate estimates were made for the stirling engine/alternator units and the balance of the subsystem, which included four items: heat transport loop, surface platform, radiator, and power management and distribution (PMAD). Total subsystem mass varied directly with the total number of power-generation units used to generate system power levels of 400 and $800 \mathrm{kWe}$. The number of power-generation units required to meet each system power level varied with the rated power output of each unit and the number of spares. Stirling engine/alternator unit mass estimates were based on the specific mass and power level relationships obtained from reference 6 .

Table IV presents the stirling engine/alternator mass estimates as a function of the number of required units. Mass values are shown only for the number of required parallel units that can provide power outputs over the 400to 800-kWe range. Table $\mathrm{V}$ presents the balance-of-subsystem mass breakdown for an 800-kWe subsystem output as a function of the number of required units. Table VI presents the balance-of-subsystem mass breakdown for a 400-kWe subsystem power output as a function of the number of required units. Tables VII and VIII present the system mass breakdown for 400- and 800-kWe system power outputs. Mass values are given for reactor and power-generation subsystems as a function of the total number, number of spares, and the power level (kwe) of power-generation units required to produce 400- and 800-kWe system power outputs. 
1. Mason, L.S.; Bloomfield, H.S.; and Hainley, D.C.: SP-100 Power system Conceptual Design for Lunar Base Applications. NASA TM-102090, 1989.

2. Juhasz, A.J.; and Bloomfield, H.S.: Reliability and Mass Analysis of Dynamic Power Conversion Systems With Parallel or Standby Redundancy. Space Nuclear Power Systems, 1985, Vol. 2, M.S. El-Genk and M.D. Hoover, eds., Orbit Book Co., Malabar, FL, 1985, pp. 205-213 (Also, NASA TM87189 ).

3. Bien, D.D.: Optimum Allocation of Redundancy Among Subsystems Connected in series. NASA TN D-7164, 1973.

4. Pringle, R.S.; and Gresho, P.M.: A Comprehensive Reliability Analysis of Redundant systems. J. Spacecraft, vol. 4, no. 5, May 1967, pp. 631-638.

5. Shooman, M.L.: Probabilistic Reliability: An Engineering Approach. MCGraw-Hill, 1969.

6. Jones, D.: Space Power Free-Piston Stirling Engine Scaling Study. (MTI-89TR6, Mechanical Technology Inc.; NASA Contract NAS3-25148.) NASA CR-182218, 1989.

TABLE I. - EFFECT OF ACCEPTABLE SYSTEM RELIABILITY CRITERION ON SUBSYSTEM CONFIGURATION SELECTION

\begin{tabular}{|c|c|c|}
\hline \multirow{2}{*}{$\begin{array}{l}\text { Acceptable } \\
\text { system } \\
\text { reliability } \\
\text { criterion }\end{array}$} & \multicolumn{2}{|c|}{ Subsystem configurations of minimum-mass powerplants ${ }^{a}$} \\
\hline & $\begin{array}{l}\text { Reactor unit reliability, } \\
0.98 \text {; power-generation } \\
\text { unit reliability, } 0.95\end{array}$ & $\begin{array}{c}\text { Reactor unit reliability, } 0.90 \\
\text { power-generation unit } \\
\text { reliability, } 0.80\end{array}$ \\
\hline 0.98 & $\begin{array}{l}(292),(282),(241),(272), \\
(262),(231),(252),(242)\end{array}$ & None meet reliability criterion \\
\hline .95 & $\begin{array}{l}(151),(192),(182),(141), \\
(172),(162),(271),(261), \\
(131),(251),(152),(292)\end{array}$ & $(242)$ \\
\hline .90 & (b) & $(262),(252),(242)$ \\
\hline .85 & (b) & $(262),(231),(252),(142),(242)$ \\
\hline .80 & (b) & $(162),(131),(152),(241),(272)$ \\
\hline
\end{tabular}

${ }^{a}$ Numbers define the subsystem configuration. The first number is the number of parallel reactor units, the second number is the total number of power-generation units, and the third number is the number of spare power-generation units.

bill single- and dual-reactor configurations. 
TABLE II. - MATRIX OF RELIABILITY AND MASS RESULTS

(a) System power level, $400 \mathrm{kWe}$

\begin{tabular}{|c|c|c|c|c|c|}
\hline $\begin{array}{c}\text { System } \\
\text { configura- } \\
\text { tion }^{a}\end{array}$ & $\begin{array}{c}\text { Power } \\
\text { output of } \\
\text { power- } \\
\text { generation } \\
\text { unit, } \\
\text { kwe }\end{array}$ & sy & $\begin{array}{l}\text { stem } \\
\text { ss, } \\
\text { sg }\end{array}$ & $\begin{array}{l}\text { Low-end } \\
\text { system } \\
\text { relia- } \\
\text { bility, } \\
\text { RS }\end{array}$ & $\begin{array}{l}\text { High-end } \\
\text { system } \\
\text { relia- } \\
\text { bility, } \\
\text { RS }\end{array}$ \\
\hline 110 & 400 & 11 & 490 & 0.7200 & 0.9310 \\
\hline 121 & 400 & 15 & 820 & .8640 & .9775 \\
\hline 131 & 200 & 12 & 930 & .8064 & .9729 \\
\hline 132 & 400 & 20 & 150 & .8928 & .9799 \\
\hline 141 & 133 & 12 & 180 & .7373 & .9663 \\
\hline 142 & 200 & 14 & 850 & .8755 & .9795 \\
\hline 151 & 100 & 11 & 960 & .6635 & .9578 \\
\hline 152 & 133 & 13 & 440 & .8479 & .9789 \\
\hline 161 & 80 & 11 & 780 & .5898 & .9479 \\
\hline 162 & 100 & 12 & 920 & .8110 & .9778 \\
\hline 171 & 67 & 11 & 850 & .5190 & .9365 \\
\hline 172 & 80 & 12 & 550 & .7668 & .9763 \\
\hline 182 & 67 & 12 & 520 & .7172 & .9743 \\
\hline 210 & 400 & 14 & 490 & .7920 & .9496 \\
\hline 221 & 400 & 18 & 770 & .9504 & .9971 \\
\hline 231 & 200 & 15 & 880 & .8870 & .9924 \\
\hline 232 & 400 & 23 & 100 & .9821 & .9995 \\
\hline 241 & 133 & 15 & 130 & .8110 & .9856 \\
\hline 242 & 200 & 17 & 800 & .9631 & .9991 \\
\hline 251 & 100 & 14 & 910 & .7299 & .9769 \\
\hline 252 & 133 & 16 & 390 & .9327 & .9985 \\
\hline 261 & 80 & 14 & 730 & .6488 & .9668 \\
\hline 262 & 100 & 15 & 870 & .8921 & .9974 \\
\hline 271 & 67 & 14 & 800 & .5709 & .9553 \\
\hline 272 & 80 & 15 & 500 & .8435 & .9958 \\
\hline 282 & 67 & 15 & 470 & .7966 & .9938 \\
\hline
\end{tabular}

${ }^{a}$ Numbers define the subsystem configuration. The first number is the number of parallel reactor units, the second number is the total number of power-generation units, and the third number is the number of spare power-generation units.

bor low estimates of reactor and power-generation unit reliability: $r=0.90 ; p=0.80$.

cFor high estimates of reactor and power-generation unit reliability: $r=0.98 ; \mathrm{p}=0.95$. 
TABLE II. - Concluded.

(b) System power level, $800 \mathrm{kWe}$

\begin{tabular}{|c|c|c|c|c|c|}
\hline $\begin{array}{c}\text { System } \\
\text { configura- } \\
\text { tion }^{a}\end{array}$ & $\begin{array}{c}\text { Power } \\
\text { output of } \\
\text { power- } \\
\text { generation } \\
\text { unit, } \\
\text { kWe }\end{array}$ & $\begin{array}{l}\text { Sys } \\
\text { ma }\end{array}$ & $\begin{array}{l}\text { stem } \\
\text { ss, } \\
\text { sg }\end{array}$ & $\begin{array}{l}\text { Low-end } \\
\text { system } \\
\text { relia- } \\
\text { bility, } \\
\text { RS }\end{array}$ & $\begin{array}{l}\text { High-end } \\
\text { system } \\
\text { relia- } \\
\text { bility, } \\
\text { RS }\end{array}$ \\
\hline 131 & 400 & 24 & 660 & 0.8064 & 0.9729 \\
\hline 141 & 270 & 22 & 320 & .7373 & .9663 \\
\hline 142 & 400 & 29 & 040 & .8755 & .9795 \\
\hline 151 & 200 & 21 & 390 & .6635 & .9578 \\
\hline 152 & 270 & 25 & 020 & .8479 & .9789 \\
\hline 161 & 160 & 20 & 850 & .5898 & .9479 \\
\hline 162 & 200 & 23 & 360 & .8110 & .9778 \\
\hline 171 & 133 & 20 & 660 & .5190 & .9365 \\
\hline 172 & 160 & 22 & 400 & .7668 & .9763 \\
\hline 181 & 114 & 20 & 720 & .4531 & .9238 \\
\hline 182 & 133 & 21 & 960 & .7172 & .9743 \\
\hline 191 & 100 & 20 & 610 & .3926 & .9104 \\
\hline 192 & 114 & 21 & 760 & .6639 & .9718 \\
\hline 231 & 400 & 27 & 960 & .8870 & .9924 \\
\hline 241 & 270 & 25 & 620 & .8110 & .9856 \\
\hline 242 & 400 & 32 & 340 & .9631 & .9991 \\
\hline 251 & 200 & 24 & 690 & .7299 & .9769 \\
\hline 252 & 270 & 28 & 320 & .9327 & .9985 \\
\hline 261 & 160 & 24 & 150 & .6488 & .9668 \\
\hline 262 & 200 & 26 & 660 & .8921 & .9974 \\
\hline 271 & 133 & 23 & 960 & .5709 & .9553 \\
\hline 272 & 160 & 25 & 700 & .8435 & .9958 \\
\hline 282 & 133 & 25 & 260 & .7966 & .9930 \\
\hline 292 & 114 & 25 & 060 & .7303 & .9898 \\
\hline
\end{tabular}

${ }^{a}$ Numbers define the subsystem configuration. The first number is the number of paraliel reactor units, the second number is the total number of power-generation units, and the third number is the number of spare power-generation units.

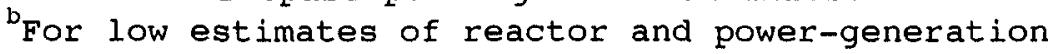
unit reliability: $r=0.90 ; p=0.80$.

${ }^{\mathrm{c}}$ For high estimates of reactor and power-generation unit reliability: $r=0.98 ; p=0.95$. 
TABLE III. - REACTOR SUBSYSTEM MASS BREAKDOWN

\begin{tabular}{|l|r|r|r|r|}
\hline \multirow{2}{*}{ Element } & \multicolumn{3}{|c|}{ System power output, kWe } \\
\cline { 2 - 5 } & \multicolumn{2}{|c|}{800} & \multicolumn{2}{c|}{400} \\
\cline { 2 - 5 } & \multicolumn{3}{|c|}{ Number of reactors } \\
\cline { 2 - 5 } & 1 & 2 & 1 & 2 \\
\hline Reactor & 760 & 1520 & 760 & 1520 \\
Instrumentation and control & 360 & 720 & 360 & 720 \\
Radiation shield & 940 & 1880 & 740 & 1480 \\
Bulkhead/shield & 770 & 1540 & 670 & 1340 \\
Heat transport loop & 350 & 700 & 300 & 600 \\
Manifolds & 420 & 550 & 370 & 490 \\
\hline Total & 3600 & 6900 & 3200 & 6150 \\
\hline
\end{tabular}

TABLE IV. - STIRLING ENGINE/ALTERNATOR UNIT MASS

\begin{tabular}{|c|c|c|c|}
\hline $\begin{array}{c}\text { Rated } \\
\text { power } \\
\text { per } \\
\text { unit, } \\
\text { kWe }\end{array}$ & $\begin{array}{c}\text { Output } \\
\text { power } \\
\text { per } \\
\text { unit, } \\
\text { kWe }\end{array}$ & $\begin{array}{c}\text { specific } \\
\text { mass at } \\
\text { rated } \\
\text { power, } \\
\text { kg/kWe }\end{array}$ & $\begin{array}{c}\text { Unit } \\
\text { mass, } \\
\mathrm{kg}\end{array}$ \\
\hline 65 & 58 & 6.3 & 410 \\
75 & 67 & 6.4 & 480 \\
90 & 80 & 6.4 & 580 \\
113 & 100 & 6.8 & 770 \\
130 & 114 & 6.9 & 897 \\
150 & 133 & 7.1 & 1065 \\
180 & 160 & 7.3 & 1314 \\
225 & 200 & 7.7 & 1733 \\
300 & 267 & 8.2 & 2460 \\
450 & 400 & 9.2 & 4140 \\
\hline
\end{tabular}

\begin{tabular}{|c|c|c|c|c|c|c|c|c|c|c|c|c|c|c|}
\hline \multirow{2}{*}{$\begin{array}{c}\text { Rated } \\
\text { power } \\
\text { per } \\
\text { unit, } \\
\text { kwe }\end{array}$} & \multicolumn{14}{|c|}{ Number of units } \\
\hline & 1 & 2 & \multicolumn{2}{|c|}{3} & \multicolumn{2}{|c|}{4} & \multicolumn{2}{|r|}{5} & \multicolumn{2}{|r|}{6} & 7 & 8 & 9 & 10 \\
\hline 65 & & & & & & & & & & & 2870 & 3280 & 3690 & 4100 \\
\hline 90 & & & & & & & 2 & 900 & 3 & 480 & 4060 & 4240 & 5220 & 5800 \\
\hline 113 & & & & & & 080 & 3 & 850 & 4 & 620 & 5390 & 6160 & 6930 & 7700 \\
\hline 130 & & & & & 3 & 588 & 4 & 485 & 5 & 382 & 6279 & 7176 & 8073 & \\
\hline 150 & & & & 195 & 4 & 260 & 5 & 325 & 6 & 390 & 7455 & 8520 & & \\
\hline 180 & & & 3 & 942 & 5 & 256 & 6 & 570 & 7 & 884 & 9198 & & & \\
\hline 225 & & 3466 & 5 & 199 & 6 & 932 & 8 & 665 & 10 & 298 & & & & \\
\hline
\end{tabular}


TABLE V. - BALANCE OF POWER-GENERATION SUBSYSTEM MASS FOR 800-kWE OUTPUT

\begin{tabular}{|c|c|c|c|c|c|c|c|c|c|c|}
\hline \multirow[t]{3}{*}{ Element } & \multicolumn{10}{|c|}{ Mass, kg } \\
\hline & \multicolumn{10}{|c|}{ Total number of power-generation units } \\
\hline & 1 & 2 & 3 & 4 & 5 & 6 & 7 & 8 & & 9 \\
\hline Heat transport & 110 & 220 & 330 & 440 & 550 & 660 & 770 & 880 & & 990 \\
\hline Surface platform & 130 & 260 & 390 & 520 & 650 & 780 & 910 & 1040 & 1 & 170 \\
\hline Radiator & 6240 & 6240 & 6240 & 6240 & 6240 & 6240 & 6240 & 6240 & 6 & 240 \\
\hline PMAD & 1680 & 1680 & 1680 & 1680 & 1680 & 1680 & 1680 & 1680 & 1 & 680 \\
\hline Total, $\mathrm{kg}$ & 8160 & 8400 & 8640 & 8880 & 9120 & 9360 & 9600 & 9840 & 10 & 080 \\
\hline
\end{tabular}

TABLE VI. - BALANCE OF POWER-GENERATION SUBSYSTEM MASS FOR 400-kWe OUTPUT

\begin{tabular}{|l|r|r|r|r|r|r|r|r|r|}
\hline \multirow{2}{*}{ Element } & \multicolumn{10}{c|}{ Mass, $\mathrm{kg}$} \\
\cline { 2 - 10 } & \multicolumn{8}{|c|}{ Total number of power-generation units } \\
\cline { 2 - 10 } & 1 & 2 & 3 & 4 & 5 & 6 & 7 & 8 & 9 \\
\hline Heat transport & 90 & 180 & 270 & 360 & 450 & 540 & 630 & 720 & 810 \\
Surface platform & 100 & 200 & 300 & 400 & 500 & 600 & 700 & 800 & 900 \\
Radiator & 3120 & 3120 & 3120 & 3120 & 3120 & 3120 & 3120 & 3120 & 3120 \\
PMAD & 840 & 840 & 840 & 840 & 840 & 840 & 840 & 840 & 840 \\
\hline Total, kg & 4150 & 4340 & 4530 & 4720 & 4910 & 5100 & 5290 & 5480 & 5670 \\
\hline
\end{tabular}


TABLE VII. - MASS BREAKDOWN OF 800-kWe SYSTEMS

(a) One spare power-generation unit

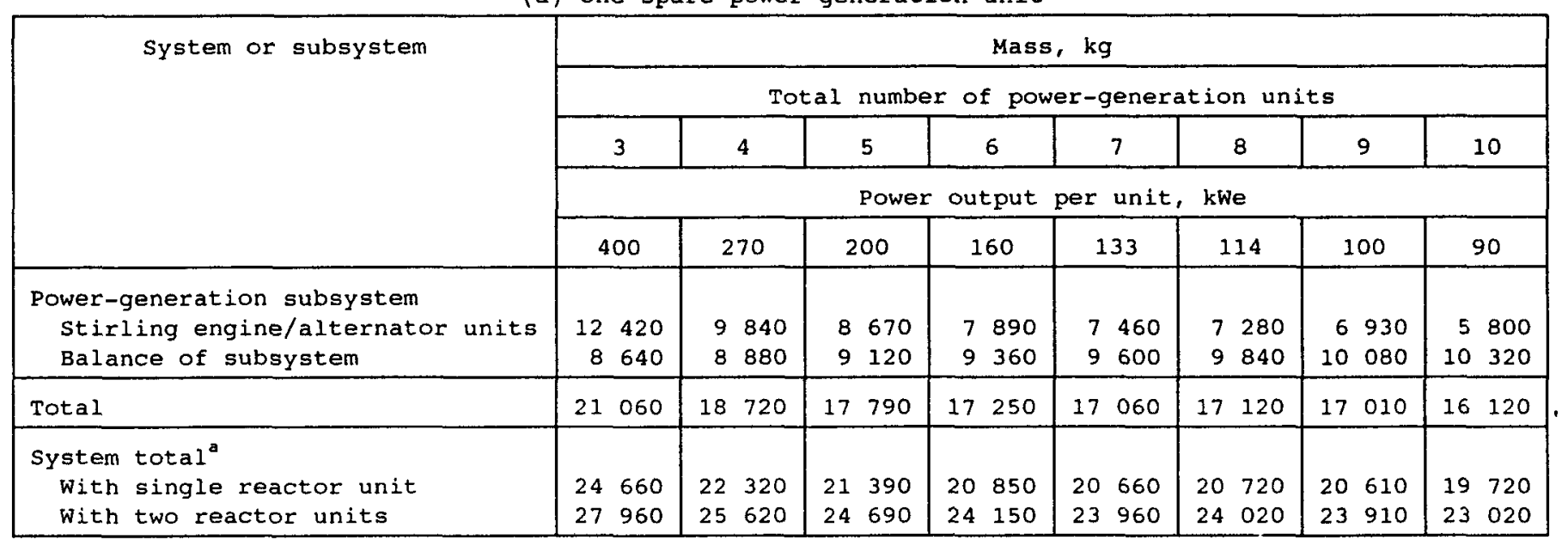

(b) Two spare power-generation units

\begin{tabular}{|c|c|c|c|c|c|c|}
\hline \multirow[t]{5}{*}{ System or subsystem } & \multicolumn{6}{|c|}{ Mass, $\mathrm{kg}$} \\
\hline & \multicolumn{6}{|c|}{ Total number of power-generation units } \\
\hline & 4 & 5 & 6 & 7 & 8 & 9 \\
\hline & \multicolumn{6}{|c|}{ Power output per unit, kwe } \\
\hline & 400 & 267 & 200 & 160 & 133 & 114 \\
\hline $\begin{array}{l}\text { Power-generation subsystem } \\
\text { Stirling engine/alternator units } \\
\text { Balance of subsystem }\end{array}$ & $\begin{array}{rr}16 & 560 \\
8 & 800\end{array}$ & $\begin{array}{rr}12 & 300 \\
9 & 120\end{array}$ & $\begin{array}{rr}10 & 400 \\
9 & 360\end{array}$ & $\begin{array}{ll}9 & 200 \\
9 & 600\end{array}$ & $\begin{array}{ll}8 & 520 \\
9 & 840\end{array}$ & $\begin{array}{rr}8080 \\
10 & 080\end{array}$ \\
\hline Total & 25440 & 21420 & 19760 & 18800 & 18360 & 18160 \\
\hline System total ${ }^{a}$ & & & & & & \\
\hline with single reactor unit & 29040 & 25020 & 23360 & 22400 & 21960 & 21760 \\
\hline With two reactor units & 32340 & 28320 & 26660 & 25700 & 25260 & 25060 \\
\hline
\end{tabular}

${ }^{a}$ Mass of reactor subsystem is $3600 \mathrm{~kg}$ with one reactor unit and $6900 \mathrm{~kg}$ with two reactor units. 


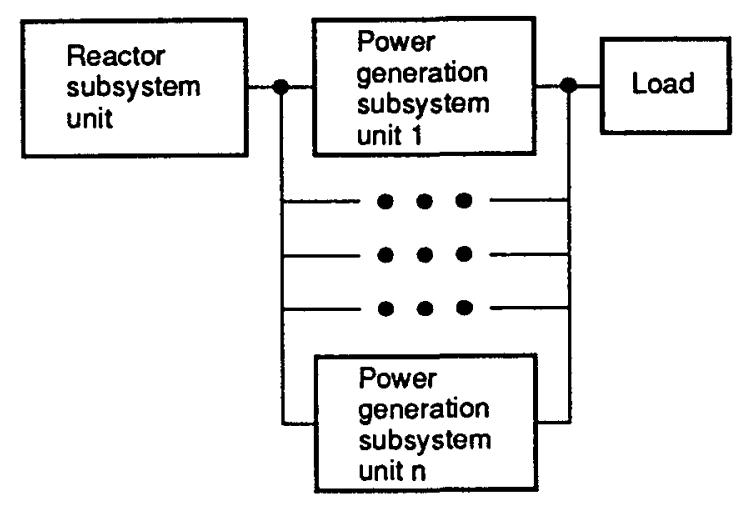

Figure 1.-Subsystem-level configuration for a single reactor unit and multiple power-generation units.

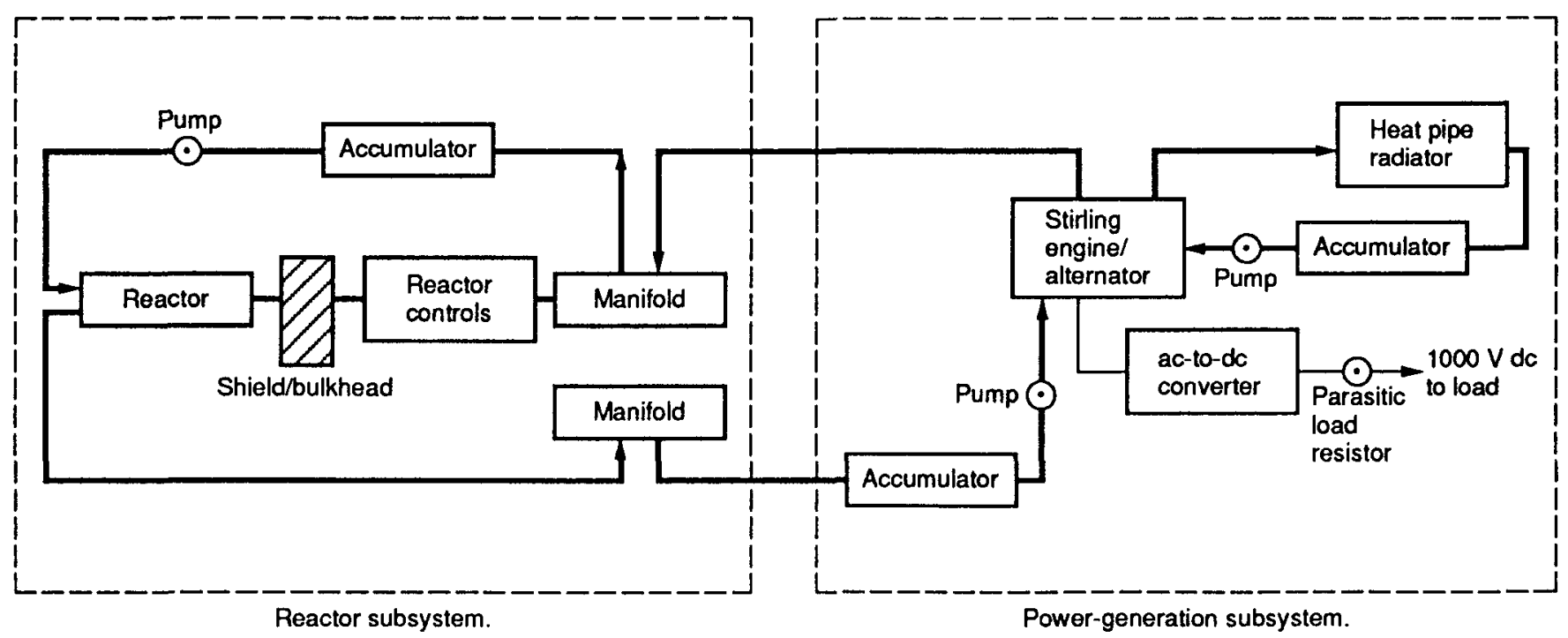

Figure 2.-Simplified schematic of lunar-base powerplant. 


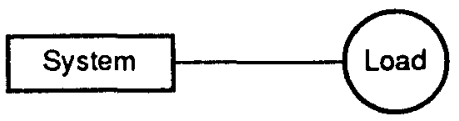

Single, nonredundant $800-k W e$ system - no spare

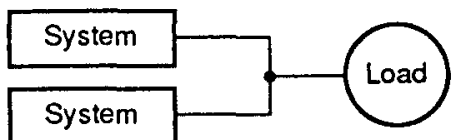

Two parallel, redundant $800-\mathrm{kWe}$ systems - one spare

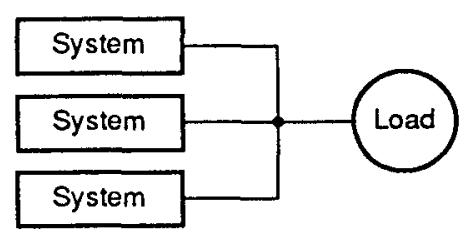

Three partially redundant $400-k W e$ systems - one spare

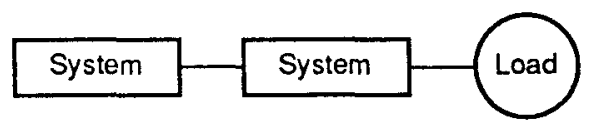

Two series, nonredundant 400-kWe systems - no spare

Figure 3. - 800-kWe lunar-base powerplant system redundancy options.

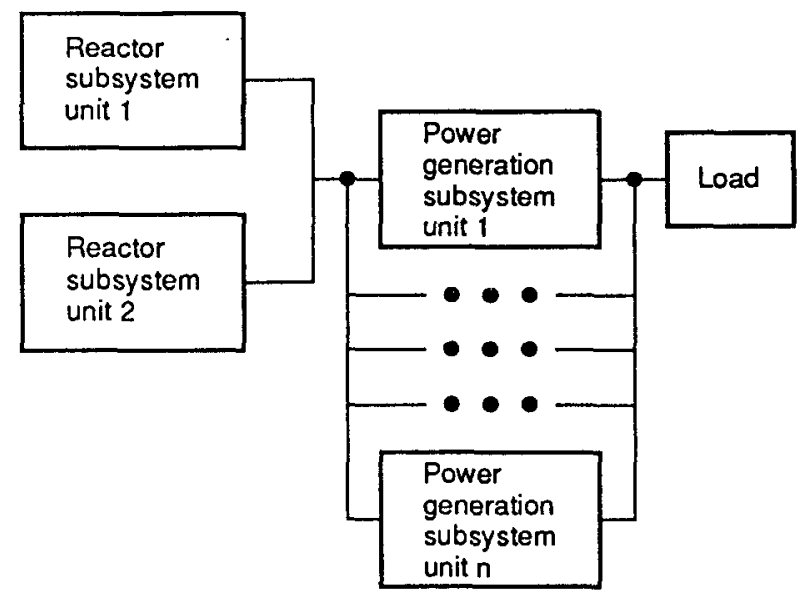

Figure 4. - Subsystem-level configuration for parallel dual reactor units and multiple power-generation units. 


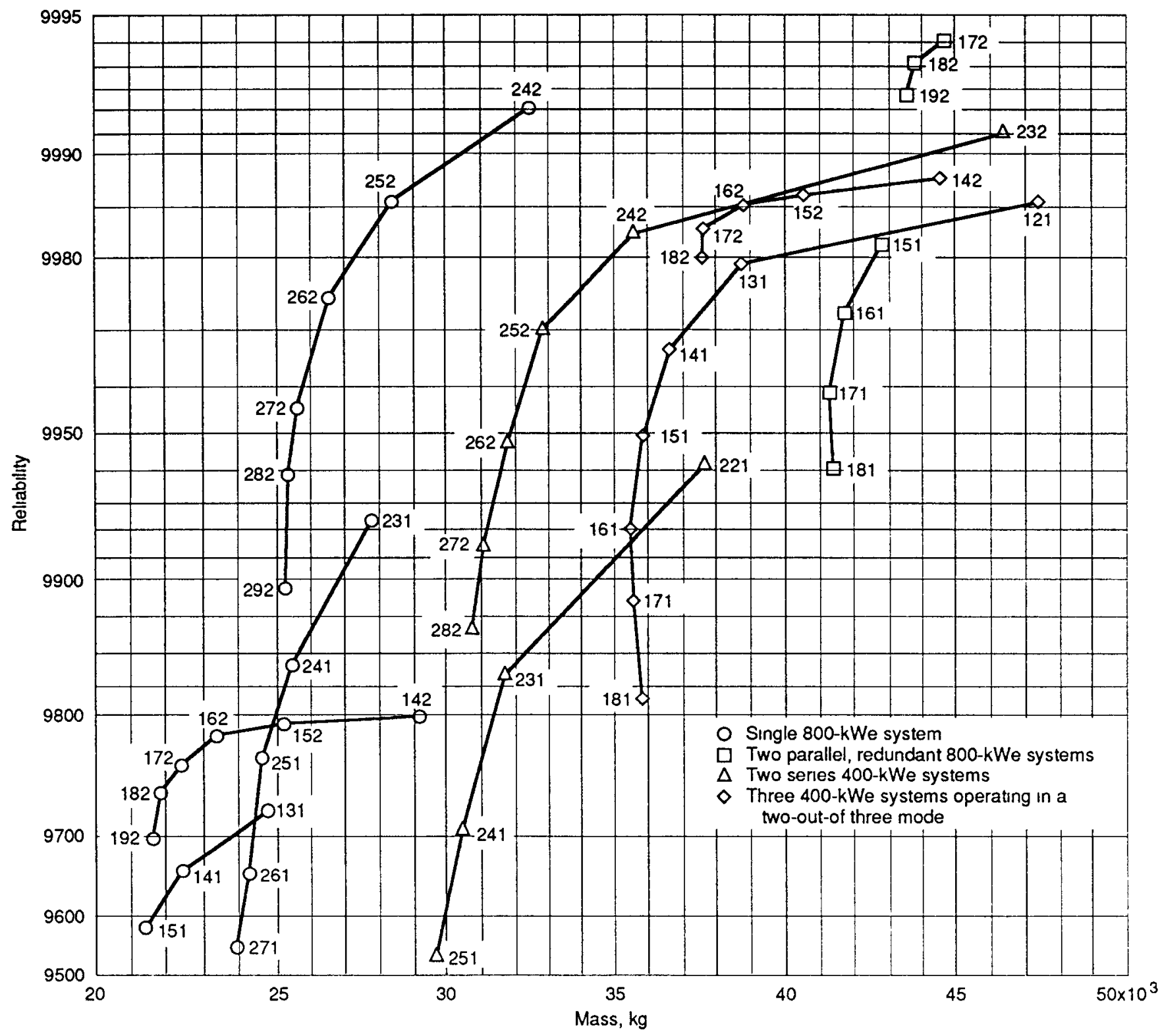

Figure 5-Reliability and mass of 800-kWe lunar-base powerplant options for a reactor subsystem unit reliability of 098 and a power-generation unit reliability of 095 Numbers corresponding to points define the system configuration The first number is the number of parallel reactor subsystems, the second number is the total number of power-generation units, and the third number is the number of spare power-generation units 


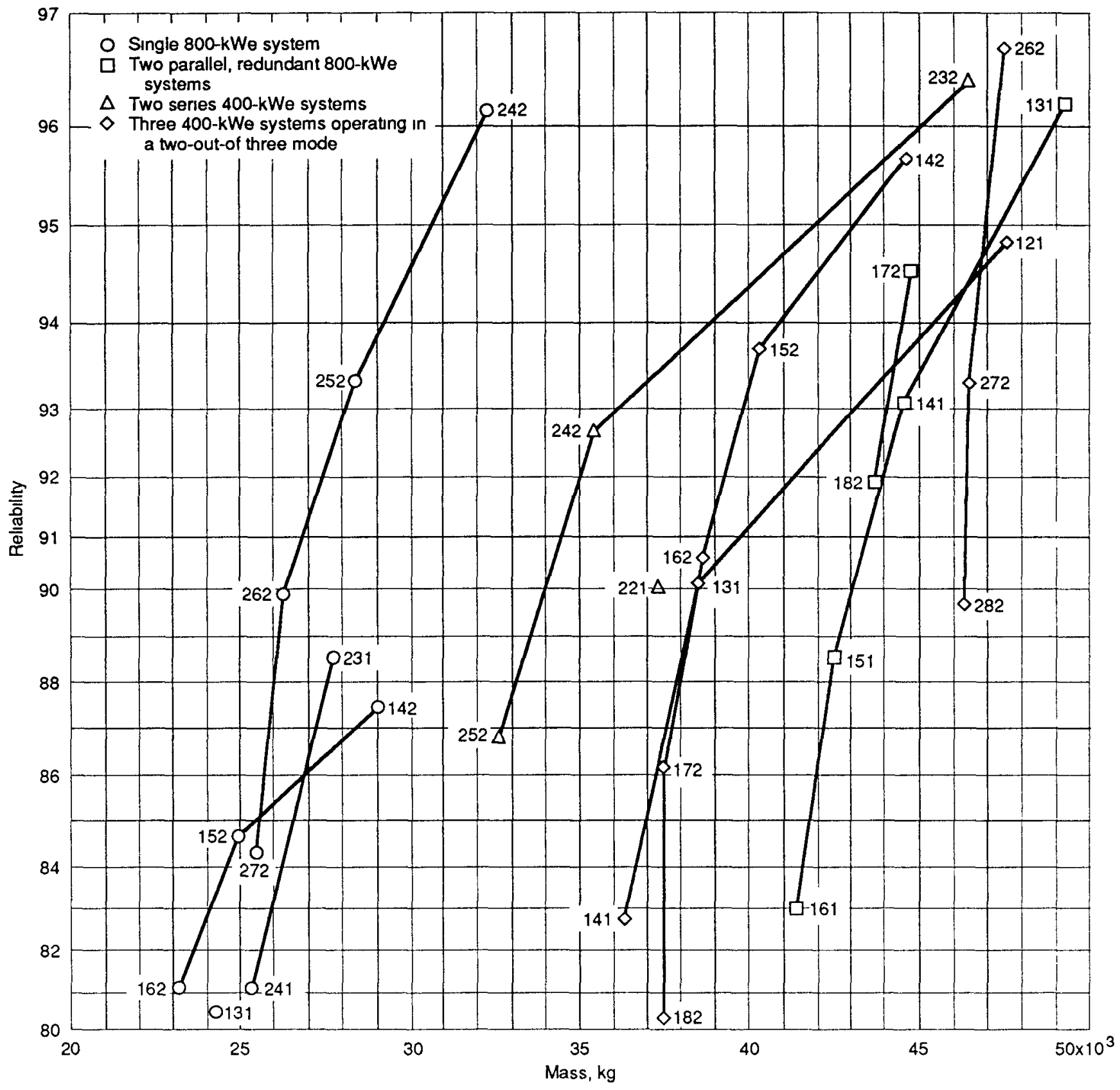

Figure 6 - Reliability and mass of $800-\mathrm{kWe}$ lunar-base powerplant options for a reactor subsystem unit reliability of 090 and a power-generation unit reliability of 080 Numbers corresponding to points define the system configuration The first number is the number of parallel reactor subsystems, the second number is the total number of power-generation units and the third number is the number of spare power-generation units 




Figure 7 -Reliability and mass envelopes for 800-kWe lunar base powerplants Numbers corresponding to points define the system configuration The first number is the number of parallel reactor subsystems, the second number is the total number of power-generation units, and the third number is the number of spare power-generation units 


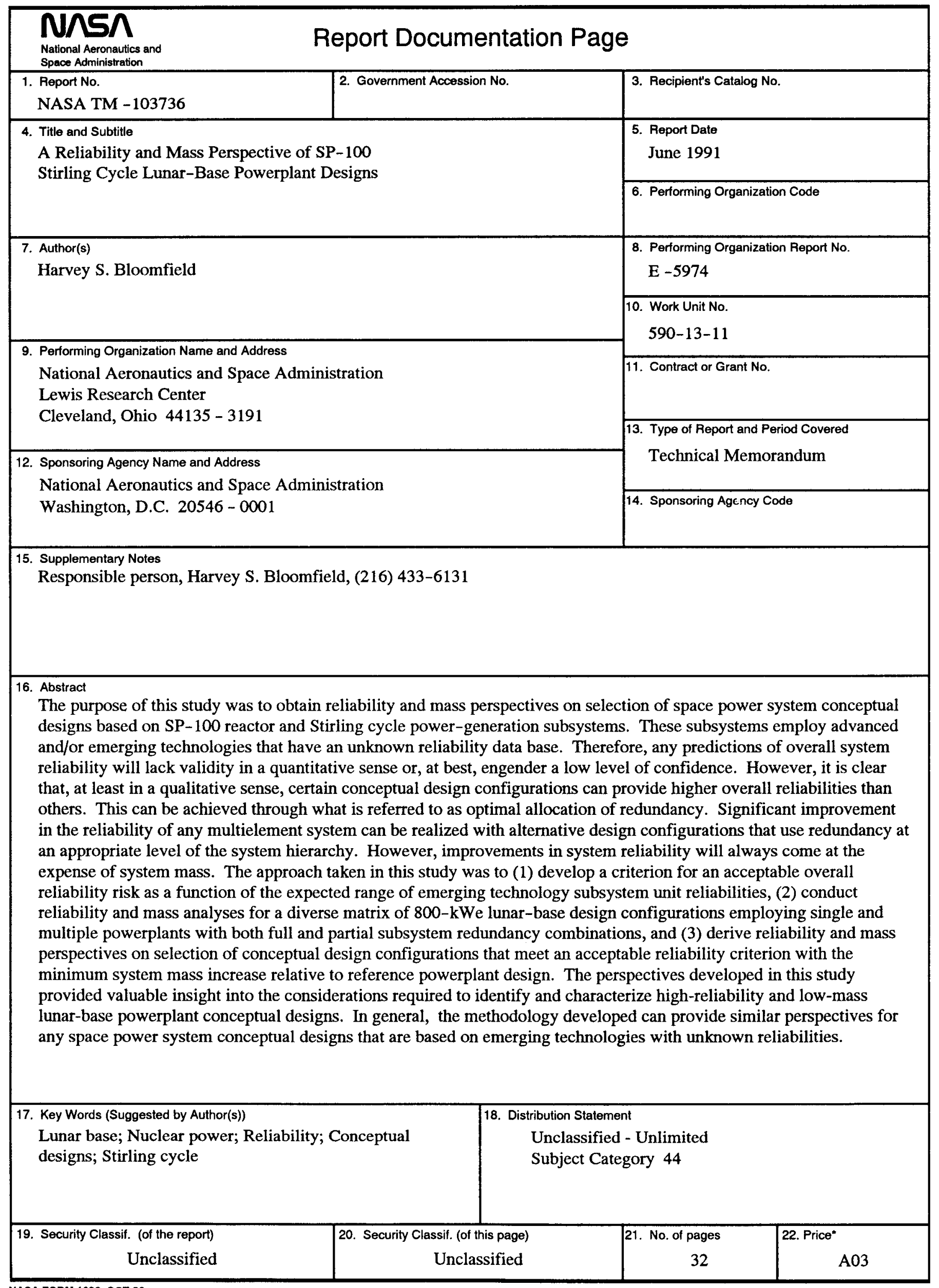

